\title{
Coaggregation of black-pigmented Bacteroides species with other oral bacteria
}

\author{
P. I. EKE, V. O. ROTIMI* and B. E. LAUGHON†
}

Department of Medical Microbiology and Parasitology, College of Medicine, University of Lagos, P.M.B. 12003 , Lagos, Nigeria and tDivision of Infectious Diseases, Johns Hopkins Hospital, Blalock 1111, Baltimore, MD 21205, USA

\begin{abstract}
Summary. Coaggregation of Bacteroides gingivalis and other black-pigmented bacteroides with several oral bacteria was studied with "reagent" strains specially prepared by methods that have been described previously. B. gingivalis coaggregated with Veillonella, Capnocytophaga and Actinomyces spp., but not with any Streptococcus spp. Coaggregation of $B$. gingivalis with other bacteria was inhibited and reversed by lactose. Of the asaccharolytic black-pigmented bacteroides, only $B$. gingivalis demonstrated any coaggregation with other bacteria, whereas within the saccharolytic species, $B$. loescheii showed a marked ability to coaggregate with several species of oral bacteria. This property of coaggregation by $\boldsymbol{B}$. gingivalis may be an important factor in the pathogenesis of periodontal infections.
\end{abstract}

\section{Introduction}

The propensity of pathogenic bacteria to retain themselves in the oral cavity is an important prerequisite for initiating infection. This is usually achieved by direct attachment to the oral mucosa or to other bacteria already attached to the mucosa; thus inter-cellular adherence amongst oral bacterial species is an important factor in the pathogenesis of oral infections. Groups of bacteria of different species resulting from such associations may also derive mutual nutritional benefits and this is known to be important in the pathogenesis of experimental synergic anaerobic infections (Mayrand and McBride, 1980; Van Steenbergen et al., 1982; Van Winkelhoff et al., 1983).

Oral pathogens such as Streptococcus and Actinomyces spp. are known to elaborate in vitro a network of highly specific cell-to-cell interactions in heterogeneous aggregates (Cisar et al., 1979; Kolenbrander and Williams, 1981, 1983; Kolenbrander et al., 1983).

Selective coaggregation among oral bacteria allows them to adhere and subsequently colonise surfaces. There is evidence which implicates Bacteroides gingivalis, a black pigmented, asaccharolytic, oral anaerobe, in the pathogenesis of adult periodontal infections (Slots, 1982), and coaggregation may be an important process in the patho-

Received 10 May 1988; accepted 24 May 1988.

* Correspondence and requests for offprints should be sent to Professor V. O. Rotimi. genesis of periodontal disease. This study was designed to investigate the coaggregation of blackpigmented Bacteroides spp., especially $B$. gingivalis, with other oral bacteria in vitro.

\section{Materials and methods}

\section{Bacterial strains}

The following oral bacterial species including clinical and reference strains of oral Bacteroides spp. were used: B. gingivalis ATCC 33277, B. asaccharolyticus ATCC 25260 , B. endodontalis A TCC $35406, B$. melaninogenicus ATCC 33184, B. intermedius ATCC 33563, B. corporis ATCC 33547, B. denticola ATCC 33185 and $B$. loescheii ATCC 15930; clinical isolates of $B$. gingivalis, strains B5, $\mathrm{C} 3, \mathrm{C} 7, \mathrm{C} 8, \mathrm{C} 9$, and $\mathrm{C} 43$, and $B$. asaccharolyticus, strains BA12 and BA2, were kindly supplied by Dr F. Martin, Maryland University Dental School, Baltimore, MD. Other bacteria used were strains of $S$. sanguis, S. morbillorum, S. mutans, Capnocytophaga spp., Fusobacterium spp. Veillonella spp., Actinomyces spp., Rothia denticariosa and Lactobacillus casei. These were kindly supplied by Dr P. E. Kolenbrander, National Institute of Dental Research, Bethesda, MD. The black-pigmented Bacteroides spp. were maintained on pre-reduced Brain Heart Infusion Agar (Scott Laboratories Inc.) with supplement (BHIS) in an anaerobic chamber at $37^{\circ} \mathrm{C}$.

\section{Preparation of "reagent" strains}

All strains were prepared as "reagent" strains by the method described by Kolenbrander et al. (1985). Briefly, bacterial strains were grown initially in suitable broths 
and harvested by centrifugation at $3000 \mathrm{~g}$ for $10 \mathrm{~min}$ during the logarithmic growth phase. Harvested cells were washed twice in phosphate-buffered saline (PBS, $\mathrm{pH} 7 \cdot 2$ ) and suspended in coaggregation buffer (sodium azide $0.02 \%, 0.15 \mathrm{M} \mathrm{NaCl}, 0.001 \mathrm{M} \mathrm{CaCl}_{2}, 0.0001 \mathrm{M}$ $\mathrm{MgCl}_{2}$ and $0.001 \mathrm{M}$ Tris, $\mathrm{pH} 8 \cdot 0$ ).

\section{Coaggregation assay}

The coaggregation assay was performed according to the method of Kolenbrander et al. (1985). The turbidity of the harvested bacterial cells, suspended in coaggregation buffer, was adjusted in a photometer to an OD value (at $260 \mathrm{~nm}$ ) which gave c. $5 \times 10^{9}$ cells $/ \mathrm{ml}$. Each cell suspension was homogenised by shaking on a vortex mixer for $20 \mathrm{~s}$. Equal volume of suspension $(300 \mu \mathrm{l})$ of the black-pigmented Bacteroides strains and the other test strains were mixed in labelled $3^{\prime \prime} \times 1 \frac{1}{2}^{\prime \prime}$ tubes and homogenised on a vortex mixer, after which the mixture was allowed to stand for $5 \mathrm{~min}$. Two strains of $\boldsymbol{B}$. gingivalis was similarly mixed and observed as above (as control) for auto-coaggregation. Coaggregation was assessed visually by gently rocking the tube against a dark background. Mixtures of bacterial species that showed no coaggregation were given a score of 0 on an arbitrary scale of $0-4$. In such tubes a homogeneous suspension was still visible. A score of 4 was given when large aggregates were formed which settled at the bottom of the tube leaving a clear supernate. Scores of 1-3 represented various degrees of coaggregation observed in the tubes.

\section{Lactose inhibition assay}

Reversal or inhibition of aggregation between any two of the bacterial species was assessed by adding $300 \mu \mathrm{l}$ of $0.06 \mathrm{M}$ lactose solution to tubes showing coaggregation, and vortex mixing for $5 \mathrm{~s}$. Coaggregation was scored as described above.

\section{Results}

The extent of coaggregation between the asaccharolytic black-pigmented Bacteroides spp. and other oral bacterial species is shown in tables I and II. Strains of $B$. gingivalis coaggregated strongly with the Veillonella spp., C. ochracea, C. gingivalis, A. viscosus, A. naeslundii strains 19, TR 9 and RC 29, A. wva strain 963, A. israelii ATCC 12103 and $R$. denticariosa, and weakly with $F$. nucleatum and some strains of $A$. israelii but not with streptococcal species. B. asaccharolyticus did not coaggregate with any of the oral species. $B$. endodontalis coaggregated in only one mixture-with $A$. israelii ATCC 12103. Coaggregation between $B$. gingivalis and other oral bacterial species was completely reversed or inhibited in the presence of $0.06 \mathrm{M}$ lactose. This was a consistent phenomenon which was also observed with B.endodontalis and A. israelii ATCC 12103.

Coaggregation of asaccharolytic and saccharolytic black-pigmented Bacteroides spp. with a selection of other oral bacterial species was compared (table II). There was no coaggregation between serotypes of $S$. mutans and $B$. gingivalis or $B$. melaninogenicus, but $B$. corporis and $B$. intermedius did so (scores $1-4$ ) with $S$. mutans serotypes $A$ and $\mathrm{D}, \boldsymbol{B}$. denticola with serotype $\mathrm{D}$, and $B$. loescheii and $B$. asaccharolyticus with serotypes A, B, C and D. B. loescheii coaggregated consistently with all the other strains tested-S. sanguis, $S$. mitis, L. casei, Actinomyces spp. and C. ochracea. There was no auto-coaggregation between two strains of $\boldsymbol{B}$. gingivalis.

\section{Discussion}

The results of this study demonstrated that $B$. gingivalis has a non-random specific affinity for coaggregation with oral bacterial species that include Veillonella, Capnocytophaga, Actinomyces and Rothia spp. Of note was the observation that $B$. gingivalis was the only member of the asaccharolytic black-pigmented Bacteroides group that coaggregated with several oral species, including those implicated in oro-dental infections. $B$. asaccharolyticus also coaggregated with some strains of $S$. mutans only. Among the saccharolytic Bacteroides spp. tested, $B$. loescheii was notable in its ability to coaggregate with several oral bacterial species.

Coaggregation between $B$. gingivalis and other species could be reversed by adding lactose, which suggests the involvement of a carbohydrate binding adhesin on the surface receptors of $B$. gingivalis (Cisar, 1982). In a previous similar study (Kolenbrander et al., 1985), the single strain of $B$. gingivalis used did not coaggregate with Actinomyces, Streptococcus or Capnocytophaga spp. However, we found that B. gingivalis coaggregated with Actinomyces and Capnocytophaga spp., but not with Streptococcus spp. Our results with $B$. asaccharolyticus were in agreement with those of Kolenbrander et al. (1985). In our study, the ability of $B$. loescheii, from amongst the saccharolytic group of black-pigmented bacteroides, to coaggregate with a wide variety of oral bacterial species supports the findings of Kolenbrander et al. (1985).

Some oral bacterial species included in this study, e.g., Streptococcus, Veillonella and Actinomyces spp., colonise the oral cavity at an early stage, and the attachment of $\boldsymbol{B}$. gingivalis to some of these early colonisers may be responsible for its retention in 
Table I. Coaggregation of asaccharolytic black-pigmented bacteroides with other oral bacteria

\begin{tabular}{|c|c|c|c|c|c|c|c|c|c|}
\hline \multirow[b]{2}{*}{ Oral bacterial species } & \multicolumn{9}{|c|}{ Coaggregation score with Bacteroides strains } \\
\hline & $\mathrm{C} 5$ & $\mathrm{C} 43$ & $\mathrm{C} 3$ & $\mathrm{C} 7$ & $\mathrm{C} 8$ & C9 & BA12 & BA & BE \\
\hline V. parvula PK 1914 & 4 & 4 & 4 & 4 & 4 & 4 & 0 & 0 & 1 \\
\hline V.atypica PK 1911 & 4 & 4. & 4 & 4 & 4 & 4 & 0 & 0 & 0 \\
\hline C. gingivalis $\mathrm{PC} 1000$ & 0 & 0 & 0 & 0 & 0 & 0 & 0 & 0 & 0 \\
\hline C. gingivalis 27 & 2 & 3 & 4 & 4 & 4 & 4 & 0 & 0 & 0 \\
\hline C. sputigena 4 & 1 & 2 & 3 & 3 & 3 & 3 & 0 & 0 & 0 \\
\hline C. ochracea 25 & 3 & 4 & 4 & 4 & 4 & 4 & 0 & 0 & 0 \\
\hline F. nucleatum PK 1904 & 0 & 0 & 2 & 1 & 2 & 1 & 0 & 0 & 0 \\
\hline F. nucleatum PK 1909 & 4 & 1 & 2 & 2 & 2 & 2 & 0 & 0 & 0 \\
\hline S. sanguis $\mathrm{PK} 488$ & 0 & 0 & 0 & 0 & 0 & 0 & 0 & 0 & 0 \\
\hline S. sanguis $\mathbf{J} 22$ & 0 & 0 & 0 & 0 & 0 & 0 & 0 & 0 & 0 \\
\hline S. sanguis $\mathrm{SS} 34$ & 0 & 0 & 0 & 0 & 0 & 0 & 0 & 0 & 0 \\
\hline S. sanguis $\mathrm{H} 1$ & 0 & 0 & 0 & 0 & 0 & 0 & 0 & 0 & 0 \\
\hline S. sanguis DL1 & 0 & 0 & 0 & 0 & 0 & 0 & 0 & 0 & 0 \\
\hline S. morbillorum SB86 & 0 & 0 & 0 & 0 & 0 & 0 & 0 & 0 & 0 \\
\hline A. viscosus 35 & 3 & 4 & 4 & 4 & 4 & 4 & 0 & 0 & 0 \\
\hline A. naeslundii 19 & 3 & 4 & 4 & 4 & 4 & 4 & 0 & 0 & 0 \\
\hline A. naeslundii TR9 & 3 & 4 & 4 & 4 & 4 & 4 & 0 & 0 & 0 \\
\hline A. naeslundii $\mathrm{RC} 29$ & 2 & 3 & 4 & 4 & 4 & 4 & 0 & 0 & 0 \\
\hline A. naeslundii TR60 & 0 & 0 & 0 & 0 & 0 & 0 & 0 & 0 & 0 \\
\hline A. naeslundii PK 2056 & 0 & 2 & 2 & 3 & 3 & 2 & 0 & 0 & 0 \\
\hline A. wva 963 & 2 & 3 & 3 & 3 & 3 & 3 & 0 & 0 & 0 \\
\hline A. israelii $\mathrm{PK} 13$ & 2 & 2 & 2 & 2 & 2 & 2 & 0 & 0 & 0 \\
\hline A. israelii PK 14 & 0 & 2 & 2 & 2 & 2 & 2 & 0 & 0 & 0 \\
\hline A. israelii PK16 & 0 & 2 & 2 & 2 & 2 & 2 & 0 & 0 & 0 \\
\hline A. israelii ATCC 12103 & 4 & 4 & 4 & 4 & 4 & 4 & 0 & 0 & 0 \\
\hline R. dentocariosa PK 44 & 0 & 2 & 4 & 4 & 4 & 3 & 0 & 0 & 0 \\
\hline
\end{tabular}

$\mathrm{C}=B$. gingivalis strains; $\mathrm{BE}=B$. endodontalis $; \mathrm{BA}=B$. asaccharolyticus $\mathrm{ATCC} 25611 ; \mathrm{BA} 12=B$. asaccharolyticus strain 12.

Table II. Coaggregation between black-pigmented Bacteroides spp. and selected oral bacteria

\begin{tabular}{|c|c|c|c|c|c|c|c|}
\hline \multirow[b]{2}{*}{ Test strains of oral species } & \multicolumn{7}{|c|}{ Coaggregation score with } \\
\hline & BG & BA & BM & BL & $\mathrm{BC}$ & BD & BI \\
\hline S. mutans serotype A & 0 & 4 & 0 & 3 & 1 & 0 & 3 \\
\hline S. mutans serotype B & 0 & 4 & 0 & 4 & 0 & 0 & 0 \\
\hline$S$ mutans serotype C & 0 & 1 & 0 & 3 & 0 & 0 & 0 \\
\hline$S$. mutans serotype D & 0 & 4 & 0 & 2 & 4 & 1 & 4 \\
\hline S. sanguis ATCC 10556 & 0 & 0 & 0 & 2 & 0 & 0 & 0 \\
\hline S. sanguis ATCC 10557 & 0 & 0 & 0 & 1 & 0 & 0 & 0 \\
\hline S. sanguis 167 & 0 & 0 & 0 & 1 & 0 & 0 & 0 \\
\hline S. mitis 903 & 0 & 0 & 0 & 1 & 0 & 0 & 0 \\
\hline L. casei 393 & 1 & 0 & 0 & 4 & 0 & 0 & 0 \\
\hline L. casei $64 \mathrm{H}$ & 0 & 0 & 0 & 4 & 0 & 0 & 0 \\
\hline L. casei ATCC 4646 & 0 & 0 & 0 & 4 & 0 & 0 & 0 \\
\hline A. viscosus $\mathrm{T} 14 \mathrm{AV}$ & 2 & 0 & 0 & 2 & 0 & 0 & 0 \\
\hline A. viscosus $\mathrm{T} 14 \mathrm{~V}$ & 2 & 0 & 0 & 4 & 0 & 0 & 0 \\
\hline C. ochracea & 3 & 0 & 0 & 3 & 0 & 0 & 0 \\
\hline
\end{tabular}

$\mathrm{BG}=$ B. gingivalis $; \quad \mathrm{BA}=\mathrm{B}$. asaccharolyticus $; \quad \mathrm{BM}=B$. melaninogenicus $; \quad \mathrm{BL}=B$. loescheii $;$ $\mathrm{BC}=B$. corporis $; \mathrm{BD}=B$. denticola $; \mathrm{BI}=B$. intermedius. 
the oral cavity. It has been suggested that $B$. loescheii may act as a bridge in coaggregating multiple bacterial species (Kolenbrander et al., 1985). The specific importance of coaggregation in vivo may be related to the enhancement of pathogenicity by adherence and the aggregation of synergically

\section{REFERENCES}

Cisar J O 1982 Coaggregation reactions between oral bacteria: studies of specific cell-to-cell adherence mediated by microbial lectins. In: Genco R J, Mergenhagen S E (eds) Host-parasite interactions in periodontal diseases. American Society for Microbiology, Washington D.C. pp 121131.

Cisar J O, Kolenbrander P E, McIntire F C 1979 Specific coaggregation reactions between human oral streptococci and strains of Actinomyces viscosus or Actinomycesnaeslundii. Infection and Immunity 24:742-752.

Kolenbrander P E, Andersen R N, Holdeman L V 1985 Coaggregation of oral Bacteroides species with other bacteria, central role in coaggregation bridges and competitions. Infection and Immunity 48:741-746.

Kolenbrander P E, Inouye Y, Holdeman L V 1983 New Actinomyces and Streptococcus coaggregation groups among human oral isolates from the same site. Infection and Immunity 41:501-506.

Kolenbrander P E, Williams B I 1981 Lactose-reversible compatible oral bacterial species. This may also partly explain the polymicrobial nature of many oro-dental infections.

We are grateful to Dr J. G. Bartlett for his support and encouragement and to Dr P. E. Kolenbrander for permission to perform part of this study in his laboratory.

coaggregation between oral Actinomyces and Streptococcus sanguis. Infection and Immunity 33:95-102.

Kolenbrander P E, Williams B I 1983 Prevalence of viridans streptococci exhibiting lactose-inhibitable coaggregation with oral Actinomyces. Infection and Immunity $41: 449-452$.

Mayrand D, McBride B C 1980 Ecological relationship of bacteria involved in a simple mixed anaerobic infection. Infection and Immunity $27: 44-50$.

Slots J 1982 Importance of black-pigmented Bacteroides in human periodontal disease. In: Genco R J, Mergenhagen $\mathrm{S} E$ (eds) Host-parasite interactions in periodontal diseases. American Society for Microbiology, Washington D.C., pp 27-45.

Van Steenbergen T J M, Kastelein P, Touw J J A, De Graaff J 1982 Virulence of black pigmented Bacteroides strains from periodontal pockets and other sites in experimentally induced skin lesions in mice. Journal of Periodontal Research 17:41-49.

Van Winkelhoff A J, Van Steenbergen T J M, De Graaff J 1983 The role of oral Bacteroides in mixed infections. Antonie Van Leeuwenhoek 49:606-611. 